\section{Synthetic pulmonary surfactant preparations: new developments and future trends}

Ismael Mingarro ${ }^{*}$, Dunja Lukovic ${ }^{1}$, Marçal Vilar ${ }^{1}$ and Jesús Pérez-Gil ${ }^{2}$ *

${ }^{1}$ Departament de Bioquímica i Biologia Molecular

Universitat de València

E-46 100 Burjassot, Spain

${ }^{2}$ Departmento de Bioquímica y Biología Molecular I,

Universidad Complutense Madrid, Spain

Running header: Pulmonary surfactant preparations.

Text: Microsoft Word X for Mac (39 pages)

Figures included in a separate file: 4 * Corresponding authors: I. Mingarro, Dept. Bioquímica i Biol. Molec.,
Universitat de València. Dr. Moliner, 50. E-46100 Burjassot, Spain. Phone: +34963543796; Fax: +34-963544635. E-mail: Ismael.Mingarro@uv.es; and J. Pérez963543796; Fax: +34-963544635. E-mail: Ismael.Mingarro@uv.es; and J. PérezGil, Dept. Bioquímica y Biol. Molec. I, Facultad de Biología. Universidad ipg@bbm1.ucm.es

\section{Abstract}

Pulmonary surfactant is a lipid-protein complex that coats the interior of the alveoli and enables the lungs to function properly. Upon its synthesis, lung surfactant adsorbs at the interface between the air and the hypophase, a capillary aqueous layer covering the alveoli. By lowering and modulating surface tension during breathing, lung surfactant reduces respiratory work of expansion, and stabilises alveoli against collapse during expiration.

Pulmonary surfactant deficiency, or dysfunction, contributes to several respiratory pathologies, such as infant respiratory distress syndrome (IRDS) in premature neonates, and acute respiratory distress syndrome (ARDS) in children and adults. The main clinical exogenous surfactants currently in use to treat some of these pathologies are essentially organic extracts obtained from animal lungs. Although very efficient, natural surfactants bear serious defects: i) they could vary in composition from batch to batch; ii) their production involves relatively high costs, and sources are limited; and iii) they carry a potential risk of transmission of animal infectious agents and the possibility of immunological reaction. All these caveats justify the necessity for a highly controlled synthetic material.

In the present review the efforts aimed at new surfactant development, including the modification of existing exogenous surfactants by adding molecules that can enhance their activity, and the progress achieved in the production of completely new preparations, are discussed.

\section{Abbreviations}

ARDS: acute respiratory distress syndrome; DPPC: 1,2-dipalmitoyl phosphatidylcholine; IRDS: infant respiratory distress syndrome; LPC: lysophosphatidylcholine; POPG: palmitoyl oleyl phosphatidylglycerol; rSP-C: recombinant surfactant protein $\mathrm{C}_{\text {; }}$ 


\section{Pulmonary surfactant function and dysfunction}

The respiratory surface of lungs constitutes the largest area of the human body exposed to the environment. Efficient gas exchange requires a large enough surface to be continuously exposed to air while minimising the barriers for oxygen and carbon dioxide to diffuse between air and the blood compartment [1]. At the same time, a selection of combined defence mechanisms is required to help keep such an essentially exposed area sterile of potential pathogenic microorganisms. Pulmonary surfactant, a lipid-protein complex produced by the alveolar epithelium of lungs, has been optimised to coordinate two main activities through natural evolution. On the one hand, it stabilises the respiratory surface against physical forces, therefore minimising the work required to maintain the large respiratory surface open to air [2-4]. On the other hand, pulmonary surfactant contains elements responsible for establishing a primary innate antipathogenic barrier, essential to ensure an intrinsically low pathogen load in the absence of induced defence mechanisms [5]. Extensive research in the last few decades has revealed some of the molecular mechanisms involved in pulmonary surfactant action. However, the manner in which both the biophysical and defence activities are intermingled and coordinately modulated in the alveolar spaces is now only beginning to be envisioned.

Pulmonary surfactant is composed of approximately $90 \%$ lipids and 8$10 \%$ proteins, although only around 5\% are specific surfactant-associated polypeptides [6,7]. Phospholipids constitute around $80 \%$ per mass of surfactant and are the main surface active molecules, able to form interfacial films capable of reducing the surface tension at the alveolar air-liquid interface until values close to $0 \mathrm{mN} / \mathrm{m}$, which are reached at the end of expiration, a strict requirement to prevent atelectasis and alveolar collapse [3]. Surfactant phospholipids assemble in the type II pneumocytes of the lung epithelium in the form of bilayered membranes. In the absence of surfactant proteins, phospholipid membranes have a very poor tendency to adsorb at the air-liquid interface as the hydrophobic chains of the lipid molecules would be transiently exposed to water on their way to the air phase from the bilayers. A small percentage, around $1-2 \%$ of surfactant per mass, of two evolutionarily conserved proteins, namely SP-B and SP-C, is sufficient to catalyse the rapid transfer of surface active phospholipids into the interface to efficiently form the operative surfactant film $[4,8]$. The lack of both proteins at birth, when air respiration has to be established, produces a lethal and irreversible respiratory failure as a consequence of the impossibility to maintain the lungs open [9], either in genetically manipulated animal models or in patients with inherited genetic deficiencies [10]. Another two proteins in the surfactant, known as SP-A and SP-D, form large macromolecular assemblies and they are capable of binding to the surface of bacteria, viruses and fungi to favour their clearance from the airways $[5,11]$.

The lack of a functional pulmonary surfactant in the immature lungs of preterm babies leads to IRDS, which was the major cause of mortality and morbidity in neonates before supplementation with exogenous surfactant was established as a therapeutic technique [12]. Today, babies at risk of developing IRDS are routinely treated with an exogenous surfactant material that helps to open and maintain their lungs open until they are able to synthesise their own endogenous surfactant $[13,14]$. Implementation of the exogenous surfactant therapeutic procedures was probably a major contribution to the sharp drop in infant mortality, which took place in the eighties. Most surfactant preparations presently used in neonatology services are obtained from extracts of animal 
surfactants, usually of a bovine or porcine origin $[13,15]$. They consist of the full hydrophobic fraction of surfactant, containing most of the lipids and variable amounts of the surface-active hydrophobic proteins SP-B and SP-C. The production methodologies of these different natural surfactant preparations, as well as their variable supplementation with supposedly beneficial components, give rise to differences in composition and biophysical activity, which have been recently reviewed elsewhere [16].

Another pathology related to pulmonary surfactant dysfunction is ARDS associated with acute lung injury (ALI) [17]. As a secondary consequence of several types of lung injury, inflammation and disruption of the alveolarcapillary barrier lead to the leakage of serum components into the airspaces, which are responsible for a severe inactivation of the biophysical activities of the surfactant complex [18]. Several trials have addressed the potential treatment of ARDS with exogenous surfactant in animal models and patients, but with limited success $[19,20]$. The limited availability of the amounts of surfactant required to treat adults, and the high susceptibility of present exogenous surfactants to inhibition by plasma components, are major caveats that preclude further developments of exogenous surfactant therapies directed to treat ARDS. A major objective of the research in this field is, therefore, the development of a new generation of therapeutic surfactants, made from human-like components, produced in enough quantity and at a reasonable cost, and which are intrinsically resistant to inactivation. The present review summarises recent developments which survey the potential of certain lipidprotein combinations containing either synthetic peptides or recombinan proteins designed to mimic human surfactant complexes as a basis for future surfactant therapies in babies and adults.

\section{The lipid moiety of pulmonary surfactant}

For a surfactant preparation to be effective enough to stabilise the respiratory surface throughout successive compression-expansion cycles, it must fulfil three main activities: i) the promotion of a very rapid formation of surface active films at the air-liquid interface, mainly during expansion at inspiration; ii) a reduction of the surface tension at the interface to very low values, around or below $1 \mathrm{mN} / \mathrm{m}$, upon compression at the end of expiration, but in a manner progressively dependent on the reduction of volume, to avoid that small alveoli collapse into larger ones; and iii) efficient re-spreading upon the expansion of the interface, to re-establish the competent state of the film, which is able to produce the lowest tensions throughout multiple cycles [4].

Early studies on the biophysical behaviour of pulmonary surfactant components in surface balances already established that the phospholipid fraction of surfactant is the main responsible to form stable surface active films able to reach very low surface tension upon compression. Those seminal studies also provided the evidences for the concept that saturated phospholipid species such as dipalmitoylphosphatidylcholine (DPPC), which is in a gel-like state at physiological temperatures, are the only ones with the potential to be packed to a very high density at the interface, which is required to produce the lowest tensions -the largest interfacial water depletion- upon compression. Since then, detailed physico-chemical studies of different simplified lipid and lipid-protein surfactant models have concluded that an appropriate lipid composition containing a fair proportion of saturated phospholipid species is essential for films to reach low enough surface tensions [6,7]. Natural pulmonary surfactant contains around $40 \%$ DPPC, which, by itself, is able to reach very low surface tensions when films made of this lipid are compressed at physiological 
temperatures. However, lipid species such as DPPC are extremely inefficient at adsorbing into the interface. The presence of some unsaturated phospholipid species and cholesterol contributes to fluidify surfactant membranes and thus improve their dynamical behaviour.

Before the discovery of the hydrophobic surfactant proteins, some protein-free preparations were designed and assessed as potential therapeutic agents. Exosurf® consisted mainly of DPPC and some amounts of cetyl alcohol and tyloxapol as spreading agents to facilitate interfacial adsorption, but its efficacy was always significantly inferior to those surfactant preparations containing proteins [21]. Other pure lipidic preparations incorporated also some proportions of anionic phospholipids [22] and other lipid additives have been assessed as potential agents to improve DPPC dynamics [23], but the idea that an efficient therapeutic surfactant could be designed in the absence of surface active proteins was abandoned soon. In fact, is the action of proteins SP-B and SP-C that greatly facilitates the rapid movement of surface-active lipids between membranes and the interface and helps to re-spread the compressed states of the films during subsequent cycling $[8,24]$. For this reason, this review will pay special attention to current ideas on the design and production of hydrophobic surfactant protein analogs to develop new artificial surfactants.

Still, some concepts can be discussed on how an efficient clinical surfactant can be optimized from the point of view of the lipid composition. There is no discussion that an efficient surfactant requires enough proportion of DPPC and some amount of the most usual anionic phospholipid in surfactant, phosphatidylglycerol (PG). This charged phospholipid has shown to provide specific interactions with the hydrophobic proteins, especially SP-B, contributing to optimize their biophysical activity $[25,26]$. A classical and simple lipid mixture, which is still used as the basis of some of the synthetic surfactants presently under development, consists of the mixture DPPC/palmitoyloleoyl PG (POPG), 70:30 (w/w). This simple system provides excellent in vitro and in vivo properties when reconstituted in the presence of some proportions of native proteins SP-B [27] and/or SP-C [28-30] or selected synthetic peptides [i.e. [31-33], and has been used as the basis of surfactant preparations such as Surfaxin [34-36], Venticute [37-41] or SP-C33 [42] (see below). However, the ratio of saturated/unsaturated phospholipids and the fraction of charged species are both markedly higher in this mixture than in natural surfactant. Animal-derived surfactants such as Curosurf, Alveofact or BLES contain DPPC and PG proportions much closer to the ones in native surfactant, in the order of $40-50$ and $10-15 \%$, respectively [16]. Interestingly Survanta, which is also obtained from a bovine surfactant extract, is supplemented with additional DPPC to reach proportions also in the order of $70 \%$ by mass.

The inclusion of significant proportions of free fatty acids as an additive in clinical surfactants deserves some discussion. Minor amounts of fatty acids such as palmitate are detected in the composition of native pulmonary surfactant, but in much less proportion than incorporated in preparations such as Survanta, Surfaxin and Venticute. The rational for this incorporation comes from in vitro tests showing that the presence of palmitic acid improves substantially the stability of interfacial films, which are thus able to maintain very low surface tensions when repeatedly compressed $[43,44]$. The problem is that these palmitic-containing mixtures reach and maintain low surface tensions at the cost of bearing a high viscosity, both as lipid/protein or lipid/peptide suspensions and as interfacial films. One has to bear in mind that composition in native surfactant is optimized in such a way that it stably sustains low 
tensions with relatively low viscosity, which facilitates spreading and redistribution along the smallest airways. Important elements that have probably to be considered to optimize further the composition of clinical surfactants include a proper amount of surfactant protein SP-B, minor but significant proportions of alkyl phospholipids and enough but not too much cholesterol. The importance of the presence of SP-B or SP-B mimics will be discussed later. Presence in surfactant of some amounts of plasmalogens and other alkyl- and alkenyl-phospholipids has been consistently correlated with optimal surfactant dynamics and low viscosity $[45,46]$. Finally, the importance for the structure and the behaviour of surfactant of a proper proportion of cholesterol is only starting to be envisaged in the last few years. In spite that cholesterol is present in proportions in the order of $5-10 \%$ of natural surfactants, it is systematically removed from all the clinical surfactant preparations used today, either synthetic or from animal origin. The reason is that cholesterol showed to impair surface activity in simple lipid systems tested in surface balances [47]. However, cholesterol is well recognized as a component that provides mechanical stability to cell membranes [48] and an important structural element to modulate their lateral structure, including segregation of specialized domains such as lipid rafts [49,50]. Recent results have shown that physiological proportions of cholesterol modulate the lateral organization and distribution of proteins and lipids in pulmonary surfactant membranes [51] and films [52,53], as well as the dynamical behaviour of surfactant films subjected to compression-expansion cycling [54]. Presence of cholesterol could be particularly important to permit surfactant films to reach and sustain the lowest surface tensions at $100 \%$ humidity [55], a condition thought to exist in the alveolar spaces but poorly reproduced in in vitro models. Excess of cholesterol has been however associated with a deleterious activity in surfactant from injured lungs [56,57], although it is not clear whether that exacerbated amounts of the steroid are a cause or a consequence of physiological responses to a partially inefficient respiratory function. We believe that there is still much room for optimization of the composition in future clinical surfactants, strictly attending to the lipid moiety, and that further understanding will come from the systematic study of the role of the full compositional complexity of native pulmonary surfactant.

\section{Structure-function relationships of SP-B}

The pulmonary surfactant protein B (SP-B) is the most important protein for surfactant activity to maintain lung airspaces open. Recent studies with genetically-modified animals, in which the expression of SP-B could be switched on or off by the presence or absence, respectively, of a conditioning inductor, have shown that the presence of a threshold proportion of SP-B is strictly required in surfactant for animals to sustain the proper respiratory dynamics [30,58]. A reduction of the level of SP-B below that threshold correlates with the rapid development of a severe respiratory failure, even in the presence of proper levels of the other hydrophobic protein, SP-C. This failure could be completely reversed upon reactivation of SP-B gene expression.

SP-B is co-isolated with lipids from the hydrophobic fraction of surfactant in the form of a covalently linked dimer of two 79-residue polypeptides [59]. The mature form of SP-B assembled and secreted into the alveolar spaces as part of the surfactant complexes, originates from the proteolytic processing of a much larger precursor of 381 amino acids. This maturation occurs in several steps throughout the exocytic pathway from the endoplasmic reticulum, where the protein is synthesised, through the Golgi and multivesicular bodies, until it appears in the lamellar bodies, the organelles 
where surfactant membranes finally assemble and are stored until secretion

[60]. The final SP-B fold contains three intramolecular disulfide bonds (Fig. 1),

and is thought to be homologous to the structure of saposin-like proteins [61], a family of membrane-active proteins including sphingolipid activator proteins, that is, saposins themselves [62-64] [65] and cytotoxins such as the amoebapore [66], NK-lysine [67] and granulysine [68]. The structure of some of these proteins has, in most cases, been solved in a membrane-free state. However, a molecular structure of SP-B, the only member of the saposin family that is permanently associated with membranes, is still not available despite the fact that some molecular modelling efforts have been reported $[69,70]$. Numerous studies have approached the analysis of structural determinants in SP-B by means of indirect techniques such as circular dichroism [71,72] [73],

fluorescence [74] or infrared spectroscopies [75,76], or electron spin resonance (ESR) [77]. The protein structure is dominated by a $40-50 \% \alpha$-helix, predicted to be in the form of amphipathic helical segments with well-defined polar and non-polar faces. These helices would promote an orientated interaction of SP-B, where the average axis of its helical segments is parallel to the plane defined by the surface of surfactant phospholipid bilayers and interfacial films [76]. This peripheral disposition could be important for the property of SP-B to stabilise surfactant film compressed states [78]. The protein possesses a net positive charge of +7 at a physiological $\mathrm{pH}$, which would facilitate its selective interaction with the fraction of negatively charged phospholipids in surfactants, mainly phosphatidylglycerol [26].

Different techniques have revealed that the interaction of SP-B with membranes promotes a significant perturbation of lipid packing and a strong alteration of their permeability barrier. SP-B thus induces leakage of the contents from liposomes as well as lipid vesicle aggregation and fusion $[79,80]$ [81]. SP-B-promoted perturbation of membrane structure could also be responsible for the ability of the protein to catalyse the exchange of phospholipids between membranes and to accelerate the transfer of surfaceactive lipid species from bilayers into air-liquid interfaces [82] [78,83]. These SPB-promoted membrane-perturbing activities have been directly mapped to the amphipathic helical segments of the protein, with some segments located near the N-terminal and C-terminal ends being the most active [30,84]. Accordingly, the present working model proposes that the biophysical activity of SP-B is mainly due to a more or less deep penetration of the hydrophobic faces of certain amphipathic helical segments into the hydrophobic core of surfactant bilayers and interfacial films. The perturbations produced on lipid packing by the insertion of the SP-B helices would mediate membrane destabilisation and inter-membrane phospholipid transfer. The extent of penetration of SP-B into phospholipid membranes is, however, a matter of debate $[72,82,85]$, and probably suggests that the protein could adopt different positions depending on the method used to reconstitute lipid-protein complexes [80]. The real physiological significance of these different SP-B/membrane organizations is still to be properly explored and probably requires a more extensive study of the orientation/ organization of SP-B in native surfactant complexes under nondenaturing conditions.

It has also been proposed that SP-B could participate in stabilising the intermediates involved in the transfer of phospholipids between lipid layers [86]. In this sense, the capacity of SP-B, as a dimer or even as a higher order oligomer, to simultaneously interact with neighbouring phospholipid surfaces could be crucial to facilitate lipid exchange. When passing between surfactant layers, phospholipids could transiently associate with potential SP-B-based 
inter-membrane bridges, which would prevent their unfavorable exposure to the aqueous environment.

The amphipathic helical motifs, however, are necessary but not sufficient for SP-B to manifest its optimal biophysical activities in surfactant preparations. Recently, it has been demonstrated that the protein needs a high enough affinity to insert into polar/non-polar interfaces in order to produce and maintain the lowest surface tensions achieved in surfactant films subjected to rapid compression-expansion dynamics. This affinity is critically dependent on the integrity of a cluster of aromatic residues located near the N-terminal end of the protein, and especially on the single tryptophan residue in the sequence of SP-B (Fig. 1) [30]. This tryptophan is strictly conserved in all the sequences of SP-B known to date, and could lead a very rapid insertion of the protein into the phospholipid-loaded air-liquid interface during the brief periods of time that the film is under expansion. Substituting the tryptophan for another amino acid with less interfacial affinity leads to a substantially reduced ability of the protein to reinsert into the interface during successive compression cycles, and a partial inefficiency to sustain proper replenishment of the interfacial film with the surface-active molecules lost during the compression moiety of the respiratory cycle [4].

The ability of SP-B to perturb phospholipid membranes has also been related to a potential antibiotic activity, which may also be mediated by an SPB-promoted alteration of the permeability barrier of bacterial envelopes $[87,88]$ These microbicidal activities of SP-B have been mainly reported in vitro and no clear notion exists as to whether SP-B might also have a potential function in the innate defence activities of pulmonary surfactant in the lung airspaces.

SP-B-related synthetic surfactants
The structural complexity of SP-B, including its high hydrophobicity and the presence of both intra- and inter-molecular disulfides (Fig. 2), has meant that, so far, it has been impossible to obtain a recombinant version of the human protein for potential use in the production of SP-B-based clinical surfactants. Therefore, attempts to produce artificial surfactants, including SP-B with human sequence, have been limited to the design and characterisation of peptides that mimic SPB-like activities. A recent study has demonstrated that SP-B retains most of the properties required to promote the formation and stability of interfacial films, even after its unfolding, and the reduction and alkylation of its cysteine residues [29]. This means that the amino acid sequence of the protein possesses intrinsic surface-active determinants beyond the behavior of the native fold, and provides the basis to think that these potentially functional determinants could be exploited if properly mimicked in simpler peptides.

Several studies have attempted to make use of the connection between protein-promoted surface activity and the membrane-perturbing properties of amphipathic helical segments by exploring the potential utility of different amphipathic helical peptides as potential additives in surfactant preparations. Admixtures of DPPC and variable proportions of these simple peptides had enough surface activity to mimic pulmonary surfactant in animal models of surfactant deficiency [89-92]. This evidence provides support for the idea that a clinical surfactant could, in principle, be produced by a proper combination of lipids and synthetic peptides. Careful analysis of the SP-B sequence determinants for surface activity revealed that a peptide synthesised from the last 20 amino acids of SP-B was able to mimic the ability of SP-B to sustain very low surface tensions during compression-expansion dynamics [82,84]. These experiments are the origin of the design of $\mathrm{KL}_{4}$, the first SP-B-inspired synthetic peptide incorporated in a surfactant preparation that has reached clinical trials 
[34-36]. This peptide, which simulates the sequence pattern of

cationic/hydrophobic residues found in the C-terminal segment of SP-B (Fig. 2), promotes the rapid transfer of phospholipids into the air-liquid interface and repetitively stabilises compressed lipid/peptide films. There has been some controversy as to the real disposition of this synthetic peptide in surfactant membranes and films. Despite the fact that $\mathrm{KL}_{4}$ was originally designed to mimic some of the amphipathic peripheral helices in SP-B, it adopted a mainly transmembrane orientation in phospholipid membranes, i.e., similar to the disposition of the other hydrophobic surfactant protein, SP-C (see below) [93]. It is conceivable that $\mathrm{KL}_{4}$ may have not a simple disposition in surfactant membranes, but still perturbs phospholipid packing enough to facilitate the transit of surface active phospholipids from bilayers into the interface. Once at the interface, the orientation of $\mathrm{KL}_{4}$ would have different restrictions to those imposed by the bilayers, and it would probably approach the originally proposed orientation $[82,94]$. At this point, it is important to consider that the orientation, the lipid-protein interactions and the potential activity of short isolated peptides could differ vastly from the properties that a similar sequence may have in the very different structural context of the entire protein fold. However, a simple peptide could be an efficient additive as a result of its own intrinsic behavior. The simple sequence of the $\mathrm{KL}_{4}$ peptide facilitates an affordable synthesis and its availability in large amounts. Surfactant preparations such as Surfaxin $\odot$, or Lucinactant ${ }^{\circledR}$, contain a small proportion of $\mathrm{KL}_{4}$ in a suspension of DPPC/ POPG/Palmitic acid (PA), and show certain efficacy as a replacement surfactant in cases of the respiratory distress syndrome in neonates [36]. The availability of this product has made its evaluation as a potential treatment for ARDS in adults with ALI possible. Treatment with surfactant of the inflamed and injured lungs of these patients has not been possible because of the large amounts of material required to treat adults, especially under conditions where an inactivation of surfactant in the airways is produced. A lavage of the injured lungs with a diluted solution of

$\mathrm{KL}_{4}$-containing surfactant has been reported to remove inactivating substances and to improve treatment among ARDS patients [95].

Nevertheless, it is difficult to assume that a peptide with the simple sequence of $\mathrm{KL}_{4}$ can really mimic the activities of SP-B, whose amino acid sequence is remarkably conserved in the evolution of air-breathing vertebrate animals. Indeed, the presence of a fair proportion of palmitic acid is required for $\mathrm{KL}_{4}$-containing preparations to sustain the very lowest surface tensions under dynamic cycling [96] as discussed above. The need to include palmitic acid to ensure proper stability of compressed surfactant films is probably related to a lack of sufficient SP-B activity. This is mainly because SP-B has been specifically reported to provide high stability to the compressed states of the films associated with the lowest surface tensions [78]. Palmitic acid is an important component of Survanta, a clinical surfactant obtained from bovine lungs, which has a substantially reduced proportion of SP-B [16]. Venticute ${ }^{\circledR}$, a surfactant preparation containing a recombinant form of surfactant protein SPC, but not SP-B, also requires palmitic acid for optimal performance [40,43]. In contrast, Curosurf, another animal-derived surfactant preparation, produced from porcine lung tissue and containing a fair proportion of SP-B, does not require the addition of palmitic acid to reproduce pulmonary surfactant dynamics either in vitro or in vivo.

Other synthetic peptides have been designed and tested to find a better mimic of the SP-B action. Numerous experiments have shown that peptide SP$\mathrm{B}_{1-25}$, with a sequence corresponding to the $25 \mathrm{~N}$-terminal residues of human SPB (Fig. 2), can mimic many of the membrane, and monolayer-perturbing 
properties as well as the surface activity behaviour of the native protein isolated from animal lungs and reconstituted in lipid/protein suspensions [33,97-99]. In fact, a recent study mapping the main structural and functional determinants in the sequence of SP-B has confirmed that the N-terminal moiety of the protein contains most of the membrane-perturbing activities required for the protein to sustain very low surface tensions in a dynamic compression-expansion in vitro model [30]. The behaviour of $\mathrm{SP}-\mathrm{B}_{1-25}$ seems to improve significantly if it is converted into a dimeric form, $\mathrm{d}$ SP- $\mathrm{B}_{1-25}$, in which two copies of the peptide are joined by a disulfide bond between the two cysteine 8 residues $[32,100]$. The combined action of several SP-B amphipathic helices is apparently important for the protein to act as a bridge that interconnects membranes and interfacial films, potentially promoting the formation of surface-associated reservoirs of surfactant $[78,101]$.

Other small cationic proteins, which have the ability to promote the exchange of phospholipids between different membranes, have been proposed as potential SP-B-mimicking analogs. Indeed, this is the rationale behind the inclusion of polymixin as a potentially useful surfactant additive [69]. A slightly different strategy was adopted in the design and synthesis of SP-B-inspired helical assemblies, which contain not one, but several potential amphipathic segments of the protein as they are cross-linked in the native fold via disulfide bonds. The so-called Mini-B is a synthetic construct containing the sequences of $\mathrm{N}$ - and C-terminal segments of SP-B, cross-linked by two disulfides equivalent to two of the three intramolecular disulfides in native SP-B [31,102]. Mini-B is probably a more faithful mimic of a real structural motif in native SP-B. In general terms, all these peptide motifs, based on the structure of SP-B, have acceptable biophysical properties when combined with surfactant lipids to be potentially useful to develop new therapeutic surfactants. Some of these peptides have shown relatively good antibiotic activities against respiratory pathogens [88] which suggests that their combined biophysical and microbiocidal action could be highly beneficial in the treatment of injured lungs.

However, the probability that new surfactant preparations containing specific synthetic peptides could be extensively used in the treatment of respiratory pathologies is low if we consider the real costs of synthesising peptides with such a specific sequence in the amounts required. A possible alternative, which has been recently considered, is the development of nonpeptidic structures that mimic SP-B activities. Several attempts have been made toward designing and characterising SP-B-like peptoids, that is, oligo-Nsubstituted glycines which are foldable in amphipathic helical conformations [103-105]. Some of these non-natural SP-B analogues show a promising surface activity in vitro and are currently being optimised further. The synthesis of peptoids would prove only slightly less expensive than producing equivalent amounts of regular peptides, but their much lower degradability could permit a sustained activity in vivo with a significantly reduced dosage. Extensive studies are still required to evaluate the real performance of these chemicals in animal models in terms of both physiological efficacy and biological safety.

A definitive strategy to successfully develop new SP-B-based synthetic surfactants will necessarily require an optimisation of the methods to produce recombinant versions of the protein in large amounts. The recent production in bacteria of a precursor of human SP-B [106] is a promising perspective.

Cleavage of this recombinant protein may provide considerable amounts of the mature SP-B sequence, even if the polypeptide is not properly folded and the disulfides are not correctly formed. The experimental evidence available today suggests that polypeptides with the SP-B sequence should, in principle, be 
extractable with organic solvents and susceptible to be reconstituted in

lipid/ protein suspensions with a sufficiently good surface activity. Even if the activity of this recombinant protein is not much better than that of the synthetic peptides, bacterial production would at least potentially provide an affordable way to accumulate the amounts of surfactant required to perform extensive research on its potential clinical use.

\section{Structure-function relationships of SP-C}

Pulmonary surfactant protein C (SP-C), the smaller of the two hydrophobic proteins present in the lung surfactant, constitutes $\sim 1 \%$ of surfactant by mass. SP-C is important in promoting the spread of the surfactant lipids to the airwater interface. This protein is synthesised as a propeptide with only one transmembrane fragment and a molecular mass of $21 \mathrm{kDa}$, which adopts a type II orientation (i.e., with the $\mathrm{N}$-terminus facing the cytoplasm and the Cterminus being translocated across the membrane) [107]. Unlike SP-B therefore, SP-C is an integral membrane protein in which the transmembrane fragment (that which remains in the mature SP-C) serves as both a signal peptide and membrane-spanning domain. Mature SP-C is formed by several proteolytic steps at both the $\mathrm{N}$-terminal and C-terminal ends of the propeptide, and is stored in the lamellar body of alveolar type II cells before being secreted into the air space along with phospholipids [108]. The N-terminal region of the propeptide (residues 1-23 in the human sequence) is required for intracellular sorting and secretion [109], while the C-terminal domain (residues 59-197, or 59191 following alternative splicing of the primary transcript [60]), likely plays an important role in the folding of the mature peptide $[110,111]$. The mature SP-C is a small (4.2 kDa), very hydrophobic and highly conserved protein (Fig. 3A), with a polar N-terminal segment and a C-terminal stretch of aliphatic residues with predominating valine residues. SP-C isolated from bronchoalveolar lavages is mostly dipalmitoylated [112]. Palmitoyl chains are attached to cysteine residues 5 and 6 (numbering is based on the sequence of the mature protein of human origin) of the propeptide before its processing to mature SP-C

[113] to increase further protein hydrophobicity. An exception to this consecutive cysteine pairing is found in several mammals [114], where a phenylalanine, substituted as a surrogate for one of the palmitates, is found in all cases. Palmitoyl chains are thought to serve as an anchor between the interfacial film and the neighbouring associated surfactant layers, thus keeping lipids in this fashion which have been squeezed out during the compression of the surface film near the interface for rapid insertion upon the next inhalation $[4,115]$. Other characteristics of the mature SP-C sequence are two prolines that flank the palmitoylated cysteine residues. Only one exception was seen in the recently reported xenopus SP-C gene [116], which codes for a protein with two prolines in this region, but not in the position that flanks the aforementioned Cys-Phe pair (Fig. 3A). In addition, two positively charged amino acids (positions 11 and 12) precede the highly hydrophobic C-terminus of the protein in all mammal species that have been sequenced [114]. The two basic residues, which probably interact with the head groups of negatively charged phospholipids [117], influence the palmitoylation of the propeptide indirectly by defining the subcellular localisation of the protein required for palmitoylation [113]. Following the two positively charged residues, the mature SP-C presents a transmembrane domain consisting of 23 hydrophobic amino acids, which is unusually rich in valine residues (Fig. 3).

The secondary structure of SP-C was initially determined in a lipid bilayer using attenuated total reflection Fourier-transform infrared spectroscopy [118]. This study found that SP-C molecules are characterised by a 
high $\alpha$-helical content, where the helical axis was found to be parallel to the acyl chains in lipid bilayers. The $\alpha$ helix was confirmed between residues 9 and 34 by NMR spectroscopy in organic solvents and in the presence of detergent micelles, while the rest of the molecule presented a disordered conformation $[119,120]$ (Fig. 4). The helix is $37 \AA$ long, which matches the thickness of a fluid DPPC bilayer, consistent with the transmembrane disposition of SP-C in membranes. Moreover, assuming that each residue in a $\alpha$-helical conformation covers a length of $1.5 \AA$, the valine-rich stretch (residues 13-28) is $24 \AA$ long, which conveniently matches the estimated $26 \AA ̊$ thickness of the acyl-chains in a fluid DPPC bilayer [121]. Interestingly, the length of the acyl-chains of a DPPC bilayer in the gel phase is $36 \AA$ [122], clearly less suitable for a transmembrane insertion of the SP-C helix. This fact could be important for the SP-C function since a mismatch between the length of the transmembrane fragment and the hydrophobic region of its environment could induce segregation and selfassociation of the protein in certain surfactant environments [123]. A similar hydrophobic mismatch is known to cause phase separation of other peptide and lipids [124], and may even affect transmembrane helix packing [125]. In lipid monolayers, the helix tilt has been suggested to depend on the surface pressure, and is influenced by the presence of the palmitic groups in the SP-C molecule [126]. Later, the SP-C helix tilt angle was shown to change from approximately $24^{\circ}$ to the interface normal in lipid bilayers to approximately $70^{\circ}$ in mixed monolayer films [127]. This study proposed that SP-C may act as a "hydrophobic lever" by maximising its interactions with the lipid acyl-chains while simultaneously providing a reasonable molecular mechanism for the protein-aided spreading of lipids [127]. However, the relative position of the palmitoyl-cysteines in relation to the valine-rich $\alpha$-helix is still uncertain as they could either be embedded within the same phospholipid bilayer or interact with neighbouring bilayers or monolayers. This latter possibility is consistent with the previously indicated hypothesis that SP-C might be responsible for an association with the interface of materials that had been squeezed out during compression to enable subsequent reinsertion. The SP-C helix could switch from monolayer into bilayers while maintaining its association with lipids during compression. Upon subsequent expansion, the helix could flip back into the interface and promote a reincorporation of collapsed phospholipids.

SP-C isolated from animal lungs has been shown to bind bacterial lipopolysaccharide (LPS) with a high affinity $[128,129]$. It has been proposed that this endotoxin-binding activity may be important to keep proinflammatory responses at the alveolar surface under control. Binding of LPS would reside in the N-terminal segment of SP-C, although the presence of the hydrophobic helix is also apparently important in promoting a proper orientation of the N-terminal segment on the surface of phospholipid layers [130]. In this sense, SP-C could play an important role in scavenging the environmental LPS from pro-inflammatory cascades that could end in exacerbated sustained responses.

In addition to its pronounced hydrophobicity, manipulation and studies of SP-C are further complicated by its structural instability. SP-C can transform irreversibly from a monomeric $\alpha$ helix into aggregated $\beta$ sheets [131], which form amyloid fibrils [132]. $\beta$ sheet formation is observed in vitro by the removal of the transmembrane domain from the phospholipid environment. SP-C fibrils are formed in an organic solution in the absence of lipids, and fibrillation does not occur when SP-C is embedded in lipid membranes. In vivo amyloid fibrils are observed in patients with pulmonary alveolar proteinosis (PAP) where protein aggregates accumulate in the alveoli [132]. Deacylation was found to be 
another factor that increases the instability of the SP-C $\alpha$ helix [133]. This conformational instability is interpreted as being a consequence of the dual conformational propensity of certain amino acids depending on their environments [134].

The SP-C transmembrane fragment is composed of 10-12 valines, depending on the species (Fig. 3A), with the other residues being Ile or Leu.

Valines and isoleucines have $\beta$-branched side chains, which makes them prone toward $\beta$ strand conformation rather than $\alpha$ helices [135]. However, in a lipid environment $\beta$-branched Val and Ile promote helix formation [136], which would explain why the molecule is mainly $\alpha$-helical in its natural environment.

\section{SP-C-related synthetic surfactants}

Although SP-B appears to have the most important surface-active effect on phospholipids, abundant data seem to suggest that a pure SP-C-containing surfactant could still possess enough activity to be effective in the treatment of surfactant-deficient pathologies. On the other hand, the joint use of SP-C with SP-B in surfactant formulations may produce synergistic effects in terms of surfactant activities, as well as further lung protection. Based on the functional roles summarised above, several SP-C analogues have been designed to be included as the main active component in various surfactant preparations. Most SP-C analogues have been designed using the known sequence and structure of this hydrophobic protein as a template.

One of the earliest efforts to obtain a synthetic analogue for SP-C was performed to gain insight into the structural basis of the molecule [120]. This study, using a chemically synthesised N-terminal non-palmitoylated SP-Cderived peptide (residues 1-17, human sequence), focused on the characterization of the structural features of the protein, in addition to questioning the contribution and function of the palmitoyl groups bonded to the cysteines. Further studies, using native SP-C, its chemically depalmitoylated form and several synthetic analogues lacking the palmitoyl-cysteine residues, were analysed to ascertain the secondary structure and biophysical activity. The output of these studies demonstrated a correlation between helical content and biophysical activity [137]. Synthetic peptides, which showed a lower helical content than the native protein, also displayed a lesser ability to accelerate lipid spreading at the air-water interface. This led to the idea that analogues, which mimic the secondary structure, rather than an exact amino acid sequence, could serve as SP-C analogues in synthetic preparations [137]

Full-length non-palmitoylated human SP-C analogues and various truncated forms of different lengths corresponding to various regions of the molecule have been evaluated both in vitro and in a rabbit preterm RDS model [138]. The sequence of residues 5-31 or 6-32, which includes the valine-rich helical structure in native SP-C, was necessary for biophysical activity. However, no data on the secondary structure of this isolated region has been reported to date. Given that the formation of a transmembrane $\alpha$-helix is more important than retaining the exact amino acid sequence [137], and that a polyvaline sequence does not favour helical conformation, several efforts have been made to replace the valine-rich region in SP-C with residues with a higher helical propensity. SP-C analogues with the valine-rich region replaced with leucines, not only folded efficiently into the alpha-helix [139], but also accelerated surface spreading at the air-water interface while significantly improving dynamic surface activity to function as an excellent surfactant when instilled together with lipids in premature rabbit neonates [140]. However, the 
leucine-rich SP-C derivatives (SP-C(Leu), Fig. 3B) have an intrinsic tendency to oligomerise and pose solubility problems when suspended in lipid mixtures [139]. The oligomerisation problem was initially circumvented by including several lysine residues in the middle of the leucine-rich region (SP-C(SLK) peptide, Fig. 3B). The presence of positive charges around the helical circumference avoided self-oligomerisation while maintaining helical conformation [141]. Surfactant preparations containing the latter peptide displayed optimal properties in vitro [141], although in vivo performance was probably compromised by complex peptide/membrane interactions involving the leucine-rich region [142]. In order to overcome the low in vivo performance of the SP-C(SLK) peptide, a derivative form bearing a single lysine residue in the $\mathrm{N}$-terminal region of the $\alpha$-helical segment was more recently designed (SPC33, Fig. 3B). This peptide is highly soluble in lipids and does not oligomerise. The surfactant preparations based on this molecule increase lung compliance in preterm rabbit foetuses to levels similar to those favoured by modified natural surfactant preparations that are currently in clinical use [42].

The same rationale for synthesising functional SP-C analogues to maximise helical conformations while minimising $\beta$-sheet conformation leading to irreversible peptide aggregation, was followed in a design where the original valine residues at the valine-rich region were periodically substituted by alanine residues [143]. Alanine is the amino acid with a higher difference between $\alpha$-helical and $\beta$-sheet propensities [135], which makes it a suitable candidate for preventing the $\beta$-sheet aggregation of the synthetic analogues. This alanine-containing SP-C-mimicking peptide (SP-C(A), Fig. 3B) was used to dope Survanta@ (Beractant $\odot$ ), a commercial therapeutic surfactant of natural origin, which increased oxygenation in a surfactant-deficient rat model [143].
No structural characterisation of this peptide has been reported to evaluate the conformation associated with its optimal activity.

Recent studies using short synthetic peptides derived from the Nterminal region of SP-C demonstrate that this region has a high affinity toward membrane interfaces, even in the absence of palmitoylated cysteines, and is able to produce perturbations in lipid packing and membrane permeability in surfactant membranes [144] and interfacial films [145]. It is, therefore, proposed that the N-terminal region could play a major role in the ability of SP-C to promote interfacial adsorption of phospholipids.

As for the case of SP-B, non-peptide (peptoids) analogues that mimic amino acid sequence patterning and conformation of SP-C have been designed [146]. This peptoid adopts a stable helical secondary structure in aqueous and organic solvents. Furthermore, it improved the kinetics of lipid adsorption to the interface and reduced the degree of film compression required to reach the minimum surface tension during cycling in a pulsating bubble surfactometer when it was introduced into lipid mixtures at a $10 \%(\mathrm{w} / \mathrm{w})$ ratio [146]. No data on the in vivo performance of these molecules has been published to date.

Another approach to the synthesis of SP-C analogues has been the use of recombinant technology. Initially, a synthetic surfactant based on bacterially expressed recombinant SP-C (rSP-C), lacking palmitoyl chains, was found to be effective in the treatment of preterm neonates in a rabbit model of RDS [41]. There has also been a report about recombinant human SP-C being produced with a certain degree of palmitoylation in the baculovirus expression system [147]. Nonetheless, more efforts have been made in recent years to optimise other bacterial expression systems. In this line, a recombinant 34-amino acid human SP-C sequence, altered by the replacement of the cysteine at positions 4 and 5 with phenylalanines and that of the methionine at position 32 with 
isoleucine (rSP-C34FF(M32I), Fig. 3B), was used to prepare a synthetic surfactant. This synthetic surfactant improved the lung function in preterm rabbits and lambs [40], and also in animal models of acute lung injury where the effect on oxygenation and histology was studied [39] and compared with that of natural or synthetic surfactants [38]. The intratracheal instillation of this bacterially-expressed recombinant SP-C-based surfactant displayed no significant risk of an anaphylactic shock reaction in a guinea pig model of acute lung hypersensitivity [37]. The rationale behind the cysteine $\rightarrow$ phenylalanine replacement in this SP-C variant is that palmitoylation represents an insurmountable challenge for bacterial expression machinery, and that the SP-C sequence from some animal species has a phenylalanine which replaces one of the palmitates [114] (Fig. 3A). In addition, the possibility remains that this particular amino acid can mimic, at least partially, the role of palmitoylated cysteines owing to the high propensity of the phenylalanine residue to partition into the membrane interface [148]. The potential utility of recombinant SP-C proteins bearing phenylalanine surrogates is strengthened by its successful use in the animal models mentioned above [38-40], and by the favourable behaviour reported for Venticute ${ }^{\circledR}$ both in vitro and in vivo. This rSP-C-containing surfactant has even been used in trials to treat patients with acute respiratory distress syndrome. Survival of these patients did not significantly improve upon receiving this surfactant, but the patients who received Venticute@ displayed a greater improvement in gas exchange in the 24-hour treatment period than patients receiving standard therapy [149]. The favourable performance exhibited by recombinant SP-C variants harbouring phenylalanines instead of palmitoylated cysteines also seems to have a structural basis, since the resolution of the structure of a Phe-containing recombinant SP-C by NMR reported no substantial differences when compared to the structure of wild-type native palmitoylated SP-C [150].

In recent work, we have bacterially overexpressed, purified and tested a recombinant SP-C construct in which only phenylalanines are substituted for palmitoylated cysteine residues (rSP-C35FF) [28]. Compared to the protein purified from porcine lungs, the recombinant SP-C forms improved the transfer of the phospholipid molecules into the interface (during adsorption), or out from the interfacial film (during compression), probably due to the presence of the aromatic residues into the $\mathrm{N}$-terminal region and a possibly better preservation of the active conformation of the protein, which suggests new possibilities of developing improved therapeutic preparations. The inclusion of these recombinant SP-C versions may be important not only to optimise the biophysical performance of clinical surfactants under the demanding dynamic conditions imposed by the lungs, but also to simultaneously modulate the inflammatory state of the respiratory epithelium.

\section{New developments and future perspectives}

Some recent developments suggest potential ways to further improve stability and resistance to inhibition of surfactant under the demanding conditions of an injured lung. Phospholipase-resistant phospholipid analogs have been designed, synthetised and tested as potential components in new clinical surfactants, showing promising activities, both in vitro and in vivo [102,151]. Supplementation with exogenous surfactant of patients with injured lungs requires the availability of enough amounts of surfactants with a reasonable resistance to inhibition. In these patients, lung oedema and the triggering of pro-inflammatory cascades lead to a markedly reduced activity of the endogenous surfactant by different mechanisms including competence of 
serum proteins to reach the air-liquid interface and degradation of surfactant lipids and proteins by lipases and proteases liberated at the alveolar spaces $[18,152]$. The development of new clinical surfactants containing those lipaseresistant species could enhance the therapeutic potential of surfactant treatments in ARDS patients.

A large perspective for strategy improvements in developing new therapeutic surfactants will arise when the appropriate procedures for producing large amounts of recombinant human surfactant proteins will have been fully established. Human analogues of surfactant protein SP-C produced by expression in bacteria are already available $[28,41]$, even though they do not have the posttranslational cysteine palmitoylation, exhibited by the native protein, isolated from animal lungs. Production of human versions of SP-B, which is considered the most important protein in surfactant from a biophysical point of view, produced either from its recombinant precursor [4] or from any other expression construct in prokaryotic or eukaryotic systems, will enable the development of a potentially new generation of SP-B/SP-C containing recombinant surfactants. The optimisation of the lipid and protein composition in these materials should, in principle, yield therapeutic preparations, which are more similar to human surfactant than the clinical surfactants available today, and hopefully in amounts which will allow clinical research on adult respiratory pathologies with certain possibilities. On the other hand, recent studies have been successful in obtaining certain amounts of recombinant human SP-A, the main hydrophilic surfactant protein, through expression in mammalian cell cultures [153-155]. This recombinant SP-A version exhibits, at least in vitro, similar functional properties to the wild-type protein.

Supplementation of clinical surfactants with recombinant SP-A would complement the biophysical activities with immunomodulatory and defence properties provided by the collectin. Either the inclusion of SP-A [156,157] or the addition of alternative compounds, such as glycopolymers [18,158,159], may represent future potential strategies to enhance surfactant resistance to inhibition by serum components, a major factor involved in the pathology of acute lung injury. An extensive exploration of the biophysical, antioxidant, antiinflammatory and antibiotic properties of surfactant preparations of a variable protein and lipid composition, possibly including proteins tailored by the genetic manipulation of their sequence in the recombinant expression systems, could provide a collection of a la carte therapeutic surfactants specifically designed for defined pathophysiological conditions.

Massive production of surfactant will also open new possibilities in the application of surfactant as a more generic tool in respiratory medicine. The intrinsic dynamic properties of surfactant to spread rapidly and efficiently along the whole respiratory surface make it a promising vehicle to deliver drugs into the distal airspaces. The potential for surfactant serving as a genedelivery $[160,161]$ or drug-delivery $[162,163]$ agent are already being explored. New generation pulmonary surfactant preparations could be optimised to maximise drug-carrying properties while maintaining surface dynamics under the respiratory context.

However, some of the most significant developments in relation to pulmonary surfactant therapies may yet be unsuspected considering the current state of knowledge of the molecular mechanisms associated with pulmonary surfactant proteins. Accessibility of recombinant surfactant protein production and genetic manipulation will open new ways to delve deeper into the understanding of their mechanism of action and into the real role they play in the respiratory physiology of all air-breathing animals on Earth. Only then 
will pulmonologists be prepared to improve their intervention strategies significantly.

\section{FIGURE LEGENDS}

Figure 1. Mature SP-B protein sequences. A) Protein sequence alignment of mature SP-B from different species. h, human; p, pig; s, sheep; d, dog; m, mouse; $r$, rat; $x$, xenopus; sequence alignment was obtained using the BLAST service from the SwissProt database. The amino acids are shown in single-letter code. The positively and negatively charged residues are marked with a plus and a minus symbol respectively on top, and the only tryptophan residue is highlighted in italic. Lines connecting the very conserved cysteine residues (shown in bold) represent disulfide bonds. B) Sequences of the SP-B analogues discussed in the text.

Figure 2. Structural model of SP-B according to the saposin-like folding and the regions of the protein that have inspired SP-B analogues. A) model of the SP-B dimer inspired by the structure of NK-lysin (PDB code: 1NKL) as a model of the saposin fold. In yellow the side chains of conserved cysteine residues are highlighted, and a bridge between them represents a disulfide bond. B) Model of the SP-B $\mathrm{B}_{1-25}$ peptide. C) Model of SP- $\mathrm{B}_{1-25}$ disulfide-dimer. D) Due to the presence of alternating positive charged residues and hydrophobic residues, the C-terminal region of SP-B (highlighted with a dotted line box) was used for the design of model peptides like $\mathrm{KL}_{4}$ (below). In both models the side chains of the positive charged residues (Arg and Lys) are shown. D) Structural model of the mini-protein Mini-B, inspired from the N- and C-terminus of SP-B (PDB code: 2DWF). Disulfide bonds are shown.

Figure 3. Comparison between sequences of SP- C from different origins and sequences of SP-C-derived peptides and recombinant proteins used for structural and functional studies. (A) Native SP-C sequence alignment highlighting the Cys residues in bold, Phe residues at positions 5 and 6 in italic 
and Pro residues underlined. $\mathrm{h}$, human; $\mathrm{p}$, pig; $\mathrm{r}$, rabbit; mk, monkey; $\mathrm{m}$, mouse; s, sheep; d, dog; mi, mink; $x$, xenopus (B) Amino acid sequences of chemically synthesised peptides and rSP-Cs mentioned in this work. Leu, SPC(leu); SLK, SP-C(SLK); 33, SP-C33; Ala, SP-C(Ala); r, rSP-C; r34, rSPC34FF(M32I); r35, rSP-C35FF (see the text for details). The same residue code as in $(\mathrm{A})$ is used.

Figure 4. Molecular graphics of SP-C structure. A) Helical region is shown in ribbon style, two plamitoylated moieties bound to cysteine 5 and 6 has been modelled using MolMol (PDB: 1SPF). B) Model of SP-C structure with free Cys residues. C) Model of SP-C structure with the Cys residues mutated to Phe.

\section{Acknowledgments}

This work was supported by grants BFU2006-08542 (to I.M.) and BIO2006-03130 (to J.P.-G.) from the Spanish Ministry of Education and Science (MEC) and ACOMP07-119 from the Generalitat Valenciana (to I.M.) and P-MAT-0002830505 from Community of Madrid and CSD2007-00010 from ConsoliderINGENIO 2010 program MEC (to J. P.-G.). Collaboration between I.M. and J.P.-G. groups has been facilitated by Marie Curie Networks EST007931 and RTN-512229.

\section{REFERENCES}

[1] Orgeig, S.; Bernhard, W.; Daniels, C.; Hall, S.; Hetz, S.K.; Lang, C.; Maina, J. Panda, A.; Possmayer, F.; Perez-Gil, J.; Veldhuizen, R. Int. Comp. Biol, 2007, 47,610 .

[2] Daniels, C.B.; Orgeig, S. News Physiol Sci, 2003, 18, 151

[3] Wustneck, R.; Perez-Gil, J.; Wustneck, N.; Cruz, A.; Fainerman, V.B.; Pison, U. Adv Colloid Interface Sci, 2005, 117, 33 .

[4] Serrano, A.G.; Perez-Gil, J. Chem Phys Lipids, 2006, 141, 105.

[5] Wright, J.R. Nat Rev Immunol, 2005, 5, 58 .

[6] Goerke, J. Biochim Biophys Acta, 1998, 1408, 79.

[7] Veldhuizen, R.; Nag, K.; Orgeig, S.; Possmayer, F. Biochim Biophys Acta, 1998, $1408,90$.

[8] Perez-Gil, J.; Keough, K.M. Biochim Biophys Acta, 1998, 1408, 203.

[9] Whitsett, J.A.; Weaver, T.E. N Engl J Med, 2002, 347, 2141.

[10] Nogee, L.M. Апnи Rev Physiol, 2004, 66, 601.

[11] Kingma, P.S.; Whitsett, J.A. Curr Opin Pharmacol, 2006, 6, 277.

[12] Zimmermann, L.J.; Janssen, D.J.; Tibboel, D.; Hamvas, A.; Carnielli, V.P. Biol Neonate, 2005, 87, 296

[13] Ainsworth, S.B.; Milligan, D.W. Am J Respir Med, 2002, 1, 417.

[14] Halliday, H.L. Biol Neonate, 2005, 87, 317 .

[15] Mazela, J.; Merritt, T.A.; Gadzinowski, J.; Sinha, S. Acta Paediatr, 2006, 95 , Mazela, J.

[16] Blanco, O.; Perez-Gil, J. Eur J Pharmacol, 2007, 568, 1

[17] Gunther, A.; Ruppert, C.; Schmidt, R.; Markart, P.; Grimminger, F.; Walmrath, D.; Seeger, W. Respir Res, 2001, 2, 353

[18] Taeusch, H.W.; de la Serna, J.B.; Perez-Gil, J.; Alonso, C.; Zasadzinski, J.A Biophys J, 2005, 89, 1769 .

[19] Lewis, J.F.; Veldhuizen, R. Аnпи Rev Physiol, 2003, 65, 613.

[20] Maruscak, A.; Lewis, J.F. Expert Opin Investig Drugs, 2006, 15, 47

[21] Halliday, H.L. Drugs, 1996, 51, 226.

[22] Morley, C.J. Dev Pharmacol Ther, 1989, 13, 182

[23] Banerjee, R.; Bellare, J.R. Respir Physiol, 2001, 126, 141.

[24] Perez-Gil, J. Biol Neonate, 2002, 81 Suppl 1, 6.

[25] Ingenito, E.P.; Mora, R.; Mark, L. Am J Respir Crit Care Med, 2000, 161, 831.

[26] Perez-Gil, J.; Casals, C.; Marsh, D. Biochemistry, 1995, 34, 3964.

[27] Perez-Gil, J.; Tucker, J.; Simatos, G.; Keough, K.M. Biochem Cell Biol, 1992, 70,332

[28] Lukovic, D.; Plasencia, I.; Taberner, F.J.; Salgado, J.; Calvete, J.J.; Perez-Gil, J.; Mingarro, I. Biochim Biophys Acta, 2006, 1758, 509.

[29] Serrano, A.G.; Cruz, A.; Rodriguez-Capote, K.; Possmayer, F.; Perez-Gil, J. Biochemistry, 2005, $44,417$.

[30] Ryan, M.A.; Qi, X.; Serrano, A.G.; Ikegami, M.; Perez-Gil, J.; Johansson, J.; Weaver, T. Biochemistry, 2005, 44,861.

[31] Waring, A.J.; Walther, F.J.; Gordon, L.M.; Hernandez-Juviel, J.M.; Hong, T.; Sherman, M.A.; Alonso, C.; Alig, T.; Braun, A.; Bacon, D.; Zasadzinski, J.A. J Pept Res, 2005, 66, 364

[32] Veldhuizen, E.J.; Waring, A.J., Walther, F.J.; Batenburg, J.J.; van Golde, L.M Haagsman, H.P. Biophys J, 2000, 79, 377. 
[33] Lipp, M.M.; Lee, K.Y.; Zasadzinski, J.A.; Waring, A.J. Science, 1996, 273, 1196.

[34] Sinha, S.K.; Lacaze-Masmonteil, T.; Valls i Soler, A.; Wiswell, T.E.; Gadzinowski, J.; Hajdu, J.; Bernstein, G.; Sanchez-Luna, M.; Segal, R.; Schaber, C.J.; Massaro, J.; d'Agostino, R. Pediatrics, 2005, 115, 1030.

[35] Moen, M.D.; Perry, C.M.; Wellington, K. Treat Respir Med, 2005, 4, 139

[36] Cochrane, C.G.; Revak, S.D.; Merritt, T.A.; Heldt, G.P.; Hallman, M.; Cunningham, M.D.; Easa, D.; Pramanik, A.; Edwards, D.K.; Alberts, M.S. Am J Respir Crit Care Med, 1996, 153, 404.

[37] Germann, P.G.; Kemkowski, J.; Hauschke, D.; Steinhilber, W.; Hafner, D. Exp Toxicol Pathol, 1999, 51, 495 .

[38] Hafner, D.; Germann, P.G.; Hauschke, D. Br J Pharmacol, 1998, 124, 1083

[39] Hafner, D.; Germann, P.G.; Hauschke, D. Am J Respir Crit Care Med, 1998 $158,270$.

[40] Davis, A.J.; Jobe, A.H.; Hafner, D.; Ikegami, M. Am J Respir Crit Care Med, 1998, $157,553$.

[41] Hawgood, S.; Ogawa, A.; Yukitake, K.; Schlueter, M.; Brown, C.; White, T.; Buckley, D.; Lesikar, D.; Benson, B. Am J Respir Crit Care Med, 1996, 154 484.

[42] Johansson, J.; Some, M.; Linderholm, B.M.; Almlen, A.; Curstedt, T.; Robertson, B. J Appl Physiol, 2003, 95, 2055.

[43] Ding, J.; Takamoto, D.Y.; von Nahmen, A.; Lipp, M.M.; Lee, K.Y.; Waring, A.J.; Zasadzinski, J.A. Biophys J, 2001, 80, 2262

[44] Alonso, C.; Alig, T.; Yoon, J.; Bringezu, F.; Warriner, H.; Zasadzinski, J.A Biophys J, 2004, 87, 4188

[45] Rudiger, M.; Kolleck, I.; Putz, G.; Wauer, R.R.; Stevens, P.; Rustow, B. Am J Physiol, 1998, 274, L143.

[46] Tolle, A.; Meier, W.; Rudiger, M.; Hofmann, K.P.; Rustow, B. Chem Phys Lipids, 2002, 114, 159 .

[47] Yu, S.H.; Possmayer, F. J Lipid Res, 2001, 42, 1421.

[48] Groves, J.T. Апnи Rev Phys Chem, 2007, 58, 697.

[49] Mayor, S.; Rao, M. Traffic, 2004, 5, 231.

[50] Michel, V.; Bakovic, M. Biol Cell, 2007, 99, 129.

[51] Bernardino de la Serna, J.; Perez-Gil, J.; Simonsen, A.C.; Bagatolli, L.A. J Biol Chem, 2004, 279, 40715.

[52] Discher, B.M.; Maloney, K.M.; Grainger, D.W.; Sousa, C.A.; Hall, S.B. Biochemistry, 1999, 38, 374

[53] Nag, K.; Perez-Gil, J.; Ruano, M.L.; Worthman, L.A.; Stewart, J ; Casals, C. Keough, K.M. Biophys J, 1998, 74, 2983.

[54] Schief, W.R.; Antia, M.; Discher, B.M.; Hall, S.B.; Vogel, V. Biophys J, 2003 84,3792

[55] Zuo, Y.Y.; Acosta, E.; Policova, Z.; Cox, P.N.; Hair, M.L.; Neumann, A.W. Biochim Biophys Acta, 2006, 1758, 1609.

[56] Panda, A.K.; Nag, K.; Harbottle, R.R.; Rodriguez-Capote, K.; Veldhuizen, R.A.; Petersen, N.O.; Possmayer, F. Am J Respir Cell Mol Biol, 2004, 30, 641.

[57] Markart, P.; Ruppert, C.; Wygrecka, M.; Colaris, T.; Dahal, B.; Walmrath, D.; Harbach, H.; Wilhelm, J.; Seeger, W.; Schmidt, R.; Guenther, A. Thorax, 2007, 62,588
[58] Nesslein, L.L.; Melton, K.R.; Ikegami, M.; Na, C.L.; Wert, S.E.; Rice, W.R.; Whitsett, J.A.; Weaver, T.E. Am J Physiol Lung Cell Mol Physiol, 2005, 288 , L1154.

[59] Hawgood, S.; Derrick, M.; Poulain, F. Biochim Biophys Acta, 1998, 1408, 150 [60] Weaver, T.E. Conkright, J.J. Annu Rev Physiol, 2001, 63, 555.

[61] Andersson, M.; Curstedt, T.; Jornvall, H.; Johansson, J. FEBS Lett, 1995, 362 ,

[62] Ahn, V.E.; Faull, K.F.; Whitelegge, J.P.; Fluharty, A.L.; Prive, G.G. Proc Natl Acad Sci U S A, 2003, 100, 38

[63] Ahn, V.E.; Leyko, P.; Alattia, J.R.; Chen, L.; Prive, G.G. Protein Sci, 2006, 15 1849

[64] Hawkins, C.A.; de Alba, E.; Tjandra, N. J Mol Biol, 2005, 346, 1381.

[65] John, M.; Wendeler, M.; Heller, M.; Sandhoff, K.; Kessler, H. Biochemistry, 2006, $45,5206$.

[66] Hecht, O.; Van Nuland, N.A.; Schleinkofer, K.; Dingley, A.J.; Bruhn, H.; Leippe, M.; Grotzinger, J. J Biol Chem, 2004, 279, 17834.

[67] Liepinsh, E.; Andersson, M.; Ruysschaert, J.M.; Otting, G. Nat Struct Biol, 1997, 4, 793.

[68] Anderson, D.H.; Sawaya, M.R.; Cascio, D.; Ernst, W.; Modlin, R.; Krensky, A.; Eisenberg, D. J Mol Biol, 2003, 325, 355.

[69] Zaltash, S.; Palmblad, M.; Curstedt, T.; Johansson, J.; Persson, B. Biochim Biophys Acta, 2000, 1466, 179.

[70] Booth, V.; Waring, A.J.; Walther, F.J.; Keough, K.M. Biochemistry, 2004, 43 , 15187.

[71] Cruz, A.; Casals, C.; Perez-Gil, J. Biochim Biophys Acta, 1995, 1255, 68

[72] Morrow, M.R.; Perez-Gil, J.; Simatos, G.; Boland, C.; Stewart, J.; Absolom, D.; Sarin, V.; Keough, K.M. Biochemistry, 1993, 32, 4397.

[73] Perez-Gil, J.; Cruz, A.; Casals, C. Biochim Biophys Acta, 1993, 1168, 261.

[74] Cruz, A.; Casals, C.; Plasencia, I.; Marsh, D.; Perez-Gil, J. Biochemistry, 1998 37,9488 .

[75] Pastrana-Rios, B.; Taneva, S.; Keough, K.M.; Mautone, A.J.; Mendelsohn, R. Biophys J, 1995, 69, 2531.

[76] Vandenbussche, G.; Clercx, A.; Clercx, M.; Curstedt, T.; Johansson, J.; Jornvall, H.; Ruysschaert, J.M. Biochemistry, 1992, 31, 9169.

[77] Cruz, A.; Marsh, D.; Perez-Gil, J. Biochim Biophys Acta, 1998, 1415, 125.

[78] Cruz, A.; Worthman, L.A.; Serrano, A.G.; Casals, C.; Keough, K.M.; Perez-Gil, J. Eur Biophys J, 2000, 29, 204.

[79] Chang, R.; Nir, S.; Poulain, F.R. Biochim Biophys Acta, 1998, 1371, 254

[80] Cruz, A.; Casals, C.; Keough, K.M.; Perez-Gil, J. Biochem J, 1997, 327 ( Pt 1), 133.

[81] Poulain, F.R.; Nir, S.; Hawgood, S. Biochim Biophys Acta, 1996, 1278, 169

[82] Cochrane, C.G.; Revak, S.D. Science, 1991, 254, 566

[83] Wang, Z.; Gurel, O.; Baatz, J.E.; Notter, R.H. J Lipid Res, 1996, 37, 1749.

[84] Vincent, J.S.; Revak, S.D.; Cochrane, C.G.; Levin, I.W. Biochemistry, 1991, 30 8395

[85] Morrow, M.R.; Stewart, J.; Taneva, S.; Dico, A.; Keough, K.M. Eur Biophys J, 2004, 33, 285.

[86] Schram, V.; Hall, S.B. Biophys J, 2001, 81, 1536

[87] Kaser, M.R.; Skouteris, G.G. Peptides, 1997, 18, 1441 
[88] Ryan, M.A.; Akinbi, H.T.; Serrano, A.G.; Perez-Gil, J.; Wu, H.; McCormack, F.X.; Weaver, T.E. J Immunol, 2006, 176, 416.

[89] McLean, L.R.; Krstenansky, J.L.; Jackson, R.L.; Hagaman, K.A.; Olsen, K.A.; Lewis, J.E. Am J Physiol, 1992, 262, L292.

[90] McLean, L.R.; Lewis, J.E. Life Sci, 1995, 56, 363.

[91] McLean, L.R.; Lewis, J.E.; Hagaman, K.A.; Owen, T.J.; Matthews, E.R. J Pharmacol Exp Ther, 1993, 266, 551 .

[92] McLean, L.R.; Lewis, J.E.; Krstenansky, J.L.; Hagaman, K.A.; Cope, A.S.; Olsen, K.F.; Matthews, E.R.; Uhrhammer, D.C.; Owen, T.J.; Payne, M.H. Am Rev Respir Dis, 1993, 147, 462.

[93] Gustafsson, M.; Vandenbussche, G.; Curstedt, T.; Ruysschaert, J.M.; Johansson, J. FEBS Lett, 1996, 384, 185 .

[94] Cochrane, C.G. FEBS Lett, 1998, 430, 424; discussion 425

[95] Wiswell, T.E.; Smith, R.M.; Katz, L.B.; Mastroianni, L.; Wong, D.Y.; Willms, D.; Heard, S.; Wilson, M.; Hite, R.D.; Anzueto, A.; Revak, S.D.; Cochrane, C.G. Am J Respir Crit Care Med, 1999, 160, 1188.

[96] Ma, J.; Koppenol, S.; Yu, H.; Zografi, G. Biophys J, 1998, 74, 1899.

[97] Longo, M.L.; Bisagno, A.M.; Zasadzinski, J.A.; Bruni, R.; Waring, A J. Science, 1993, 261, 453.

[98] Gupta, M.; Hernandez-Juviel, J.M.; Waring, A.J.; Bruni, R.; Walther, F.J. Eur Respir J, 2000, 16, 1129.

[99] Gupta, M.; Hernandez-Juviel, J.M.; Waring, A.J.; Walther, F.J. Thorax, 2001, $56,871$.

[100] Biswas, N.; Waring, A.J.; Walther, F.J.; Dluhy, R.A. Biochim Biophys Acta, 2007, 1768, 1070.

[101] Krol, S.; Ross, M.; Sieber, M.; Kunneke, S.; Galla, H.J.; Janshoff, A. Biophys J. 2000, 79, 904

[102] Walther, F.J.; Waring, A.J.; Sherman, M.A.; Zasadzinski, J.A.; Gordon, L.M Neonatology, 2007, 91, 303.

[103] Seurynck, S.L.; Patch, J.A.; Barron, A.E. Chem Biol, 2005, 12, 77.

[104] Seurynck-Servoss, S.L.; Brown, N.J.; Dohm, M.T.; Wu, C.W.; Barron, A.E. Colloids Surf B Biointerfaces, 2007, 57, 37.

[105] Seurynck-Servoss, S.L.; Dohm, M.T.; Barron, A.E. Biochemistry, 2006, 45 11809.

[106] Serrano, A.G.; Cabre, E.J.; Oviedo, J.M.; Cruz, A.; Gonzalez, B.; Palacios, A.; Estrada, P.; Perez-Gil, J. Biochim Biophys Acta, 2006, 1758, 1621.

[107] Keller, A.; Eistetter, H.R.; Voss, T.; Schafer, K.P. Biochem J, 1991, 277 ( Pt 2), 493.

[108] Weaver, T.E. Biochim Biophys Acta, 1998, 1408, 173

[109] Conkright, J.J.; Bridges, J.P.; Na, C.L.; Voorhout, W.F.; Trapnell, B.; Glasser, S.W.; Weaver, T.E. J Biol Chem, 2001, 276, 14658

[110] Mulugeta, S.; Nguyen, V.; Russo, S.J.; Muniswamy, M.; Beers, M.F. Am J Respir Cell Mol Biol, 2005, 32, 521.

[111] Johansson, H.; Nordling, K. Weaver, T.E.; Johansson, J. J Biol Chem, 2006 , $281,21032$.

[112] Johansson, J.; Curstedt, T. Eur J Biochem, 1997, 244, 675.

[113] ten Brinke, A.; van Golde, L.M.; Batenburg, J.J. Biochim Biophys Acta, 2002, $1583,253$.

[114] Foot, N.J.; Orgeig, S.; Donnellan, S.; Bertozzi, T.; Daniels, C.B. J Mol Evol, $\mathbf{2 0 0 7}, 65,12$.
[115] Kramer, A.; Wintergalen, A.; Sieber, M.; Galla, H.J.; Amrein, M Guckenberger, R. Biophys J, 2000, 78, 458.

[116] Hyatt, B.A.; Resnik, E.R.; Johnson, N.S.; Lohr, J.L.; Cornfield, D.N. Gene Expr Patterns, 2007, 7, 8 .

[117] Creuwels, L.A.; Boer, E.H.; Demel, R.A.; van Golde, L.M.; Haagsman, H.P. J Biol Chem, 1995, 270, 16225

[118] Vandenbussche, G.; Clercx, A.; Curstedt, T.; Johansson, J.; Jornvall, H.; Ruysschaert, J.M. Eur J Biochem, 1992, 203, 201.

[119] Johansson, J.; Szyperski, T.; Curstedt, T.; Wuthrich, K. Biochemistry, 1994, 33

[120] Johansson, J.; Szyperski, T.; Wütrich, K. FEBS Lett, 1995, 362, 261

[121] Lewis, B.A.; Engelman, D.M. J Mol Biol, 1983, 166, 211.

[122] Janiak, M.J.; Small, D.M.; Shipley, G.G. Biochemistry, 1976, 15, 4575.

[123] Horowitz, A.D.; Baatz, J.E.; Whitsett, J.A. Biochemistry, 1993, 32, 9513.

[124] Zhang, Y.-P.; Lewis, R.N.A.H.; Hodges, R.S.; McElhaney, R.N. Biochemistry, 1992, 31, 11579

[125] Orzaez, M.; Lukovic, D.; Abad, C.; Perez-Paya, E.; Mingarro, I. FEBS Lett, 2005, 579, 1633.

[126] Creuwels, L.A.; Demel, R.A.; van Golde, L.M.; Benson, B.J.; Haagsman, H.P. $J$ Biol Chem, 1993, 268, 26752.

[127] Gericke, A.; Flach, C.R.; Mendelsohn, R. Biophys J 1997, 73, 492.

[128] Augusto, L.; Le Blay, K.; Auger, G.; Blanot, D.; Chaby, R. Am J Physiol Lung Cell Mol Physiol, 2001, 281, L776.

[129] Augusto, L.A.; Li, J.; Synguelakis, M.; Johansson, J.; Chaby, R. J Biol Chem, 2002, 277, 23484

[130] Chaby, R.; Garcia-Verdugo, I.; Espinassous, Q.; Augusto, L.A. J Endotoxin Res, 2005, 11,18

[131] Szyperski, T.; Vandenbussche, G.; Curstedt, T.; Ruysschaert, J.M.; Wuthrich, K.; Johansson, J. Protein Sci, 1998, 7, 2533.

[132] Gustafsson, M.; Thyberg, J.; Naslund, J.; Eliasson, E.; Johansson, J. FEBS Lett, $\mathbf{1 9 9 9 ,} 464,138$.

[133] Gustafsson, M.; Griffiths, W.J.; Furusjo, E.; Johansson, J. J Mol Biol, 2001, 310 , 937.

Johansson, J.; Weaver, T.E.; Tjernberg, L.O. Cell Mol Life Sci, 2004, 61, 326.

[135] Kallberg, Y.; Gustafsson, M.; Persson, B.; Thyberg, J.; Johansson, J. J. Biol. Chem., 2001, 276, 12945.

[136] Li, S.-C.; Deber, C.M. Nat Struct Biol, 1994, 1, 368.

[137] Johansson, J.; Nilsson, G.; Stromberg, R.; Robertson, B.; Jornvall, H.; Curstedt T. Biochem J, 1995, 307, 535

[138] Takei, T.; Hashimoto, Y.; Aiba, T.; Sakai, K.; Fujiwara, T. Biol Pharm Bull, 1996, $19,1247$.

[139] Nilsson, G.; Gustafsson, M.; Vandenbussche, G.; Veldhuizen, E.; Griffiths, W.J.; Sjovall, J.; Haagsman, H.P.; Ruysschaert, J.M.; Robertson, B.; Curstedt, T.; Johansson, J. Eur J Biochem, 1998, 255, 116

[140] Takei, T.; Hashimoto, Y.; Ohtsubo, E.; Sakai, K.; Ohkawa, H. Biol Pharm Bull, 1996, 19,1550

[141] Palmblad, M.; Johansson, J.; Robertson, B.; Curstedt, T. Biochem J, 1999, 339 Pt 2), 381

[142] Curstedt, T.; Johansson, J. Biol Neonate, 2005, 87, 332. 
[143] Walther, F.J.; Hernandez-Juviel, J.; Bruni, R.; Waring, A.J. Am J Respir Crit Care Med, 1997, 156, 855.

[144] Plasencia, I.; Rivas, L.; Keough, K.M.; Marsh, D.; Perez-Gil, J. Biochem J, 2004, 377, 183 .

[145] Plasencia, I.; Keough, K.M.; Perez-Gil, J. Biochim Biophys Acta, 2005, 1713 , 118.

[146] Wu, C.W.; Seurynck, S.L.; Lee, K.Y.; Barron, A.E. Chem Biol, 2003, 10, 1057.

[147] Veldhuizen, E.J.; Batenburg, J.J.; Vandenbussche, G.; Putz, G.; van Golde,

L.M.; Haagsman, H.P. Biochim Biophys Acta, 1999, 1416, 295.

[148] White, S.H.; Wimley, W.C. Biochim Biophys Acta, 1998, 1376, 339.

[149] Spragg, R.G.; Lewis, J.F.; Walmrath, H.D.; Johannigman, J.; Bellingan, G.; Laterre, P.F.; Witte, M.C.; Richards, G.A.; Rippin, G.; Rathgeb, F.; Hafner, D. Taut, F.J.; Seeger, W. N Engl J Med, 2004, 351, 884.

[150] Luy, B.; Diener, A.; Hummel, R.P.; Sturm, E.; Ulrich, W.R.; Griesinger, C. Eur J Biochem, 2004, 271, 2076.

[151] Notter, R.H.; Schwan, A.L.; Wang, Z.; Waring, A.J. Mini Rev Med Chem, 2007, $7,932$.

[152] Taeusch, H.W.; Keough, K.M. Pediatr Pathol Mol Med, 2001, 20, 519

[153] Garcia-Verdugo, I.; Sanchez-Barbero, F.; Bosch, F.U.; Steinhilber, W.; Casals, C. Biochemistry, 2003, 42, 9532 .

[154] Sanchez-Barbero, F.; Rivas, G.; Steinhilber, W.; Casals, C. Biochem J, 2007, 406,479 .

[155] Sanchez-Barbero, F.; Strassner, J.; Garcia-Canero, R.; Steinhilber, W.; Casals, C. J Biol Chem, 2005, 280,7659.

[156] Cockshutt, A.M.; Weitz, J.; Possmayer, F. Biochemistry, 1990, 29,8424

[157] Schurch, S.; Possmayer, F.; Cheng, S.; Cockshutt, A.M. Am J Physiol, 1992 263, L210

[158] Lu, K.W.; Goerke, J.; Clements, J.A.; Taeusch, H.W. Pediatr Res, 2005, 58 206.

[159] Kang, N.; Policova, Z.; Bankian, G.; Hair, M.L.; Zuo, Y.Y.; Neumann, A.W.; Acosta, E.J. Biochim Biophys Acta, 2007.

[160] Katkin, J.P.; Husser, R.C.; Langston, C.; Welty, S.E. Hum Gene Ther, 1997, 8, 171.

161] Gautam, A.; Waldrep, C.J.; Densmore, C.L. Am J Respir Med, 2002, 1, 35.

[162] Nimmo, A.J.; Carstairs, J.R.; Patole, S.K.; Whitehall, J.; Davidson, K.; Vink, R. Clin Exp Pharmacol Physiol, 2002, 29, 661.

[163] Gommers, D.; Haitsma, J.J.; Lachmann, B. Clin Physiol Funct Imaging, 2006, 26, 357. 
A
h

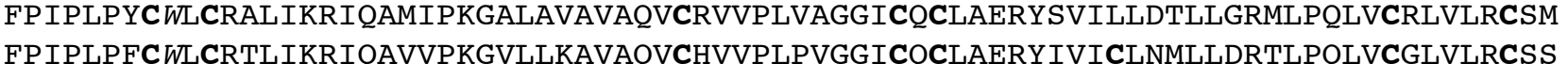 FPIPLPFCWLCRTLIKRIOAVIPKGVLAMTVAOVCHVVPLLVGGICOCLVERYSVILLDTLLGRMLPOLVCGLVLRCSS LPIPLPYCWLCRTLIKRIQAMIPKGVLAVTVGQVCHVVPLVVGGICOCLGERYTVLLLDALLGRMLPQLVCGLVLRCSH LPIPLPFCWLCRTLIKRVQAVIPKGVLAVAVSOVCHVVPLVVGGICOCLAERYTVLLLDALLGRVVPOLVCGLVLRCST LPIPLPFC $W L C R T L I K R V Q A V I P K G V L A V A V S Q V C H V V P L V V G G I C O C L A E R Y T V L L L D A L L G R V V P Q L V C G L V L R C S T$ LPIPKPMC $W M C K S F$ ISQLEKVIPKTVIAKAASQLCRILPAKVAGVCOCLVEKYTVILLDIVLEKLGPQLLCKLLFMCAT

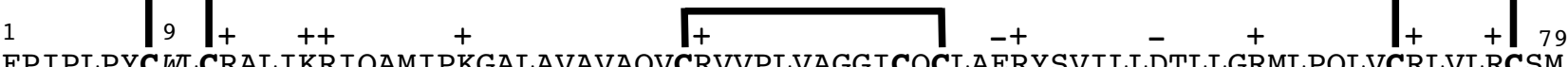

B

$\mathrm{SPB}_{1-25}$ FPIPLPYCWLCRALIKRIQAMIPKG

MiniB CWLCRALIKRIQAMIPKG

$\mathrm{SPB}_{59-79}$

GRMLPQLVCRLVLRCS

TLLGRMLPQLVCRLVLRCSM 


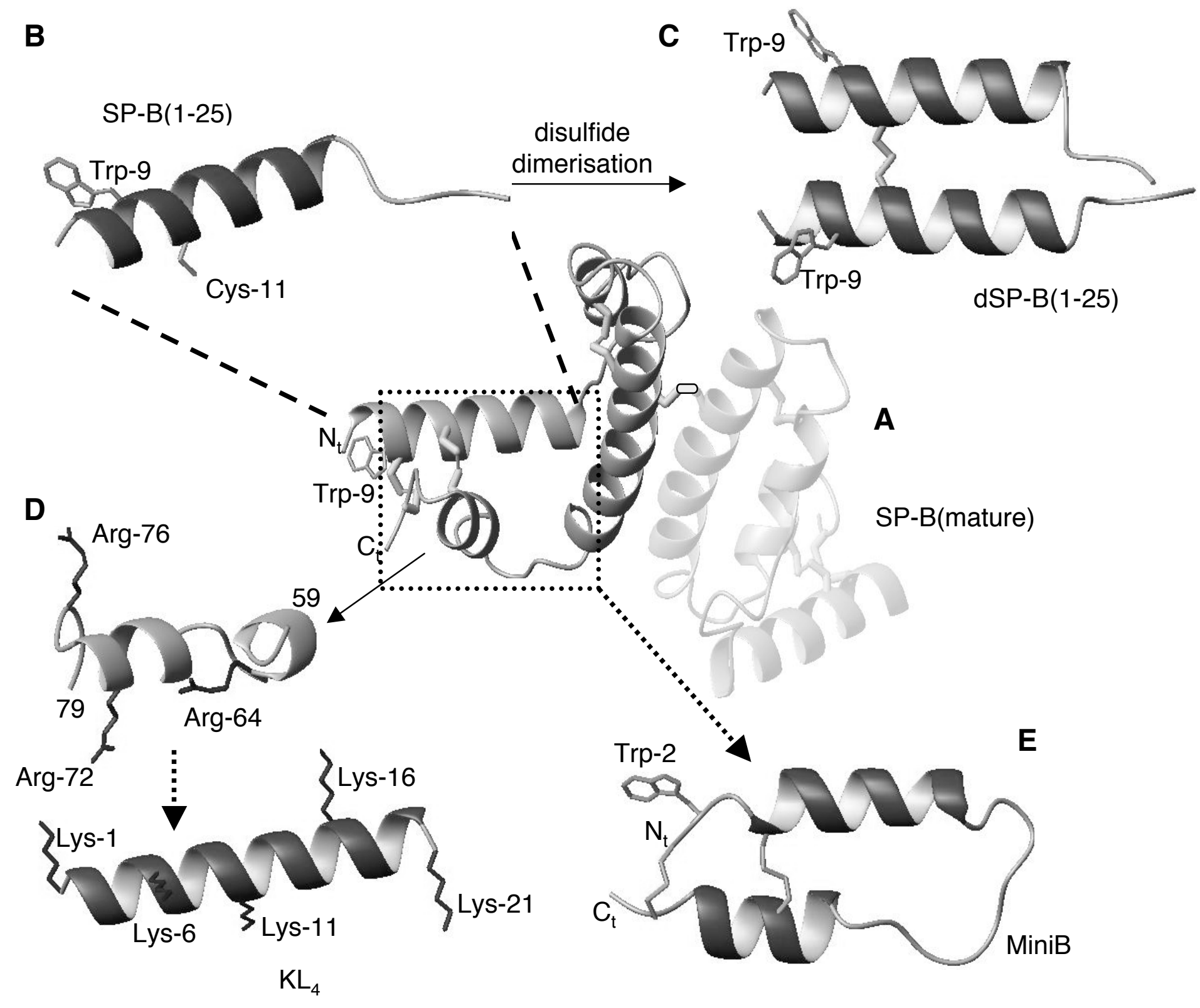


A

FGIPCCPVHLKRLLIVVVVVVLIVVVIVGALLMGL LRIPCCP PNLKRLLVVVVVVVLVVVVIVGALLMGL $p$ FGIPCCPVHLKRLLIVVVVVVLVVVVIVGALLMGL $r$ FGIPCCPVHLKRLLIVVVVVVLVVVVIVGALLMGL $\mathrm{mk}$ FRIPCCPVHLKRLLIVVVVVVLVVVVIVGALLMGL $\mathrm{m}$ LRIPCCPVNIKRLLIVVVVVVLVVVVIVGALLMGL s LGIPC FPSSLKRLLI IVVVIVLVVVVIVGALLMGL d LGIP्CFPSSLKRLLI IVVVIVLVVVVIVGALLMGL $\mathrm{mi}$ ELPIPCFGGVKKLVCVVLVVVVLVLVLVGVLLMGL $\mathrm{x}$

B

FGIPSSPV-LKRLLILLLLLLLILILIL 200 FGIPSSPVHLKRLLILKLLLLKILLLKLGALLMGL SLK IPSSPVHLKRLKLLLLLLLLLLLLILGALLMGL 33 FGIPCCPVVHLKRLLAVAVAVALAVAVAVGALLMGL Ala FGIPCCPVHLKRLLIVVVVVVLIVVVIVGALLMGL $r$

GIPFFPVHLKRLLIVVVVVVLIVVVIVGALLIGL $\mathrm{r} 34$ FGIPFFPVHLKRLLIVVVVVVLIVVVIVGALLMGL $\mathrm{r} 35$ 


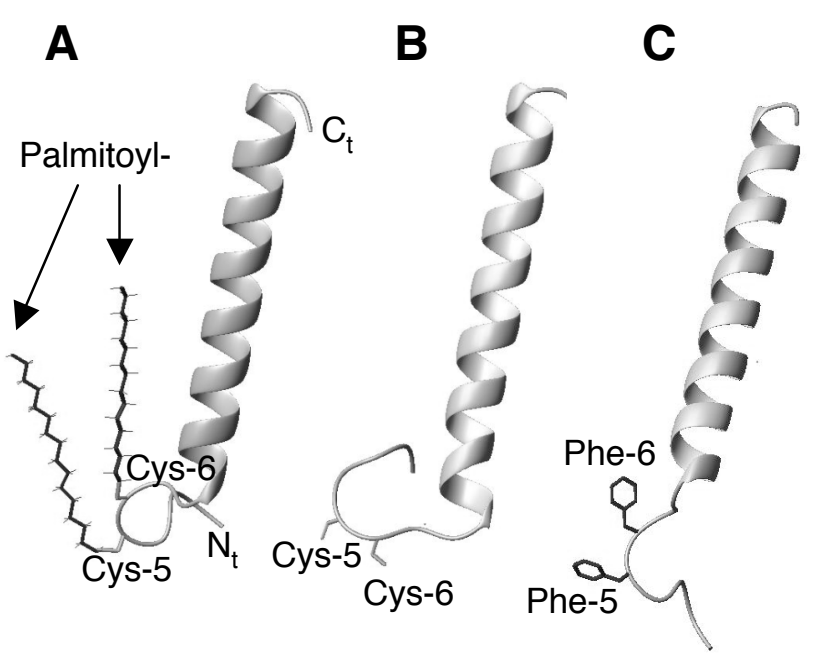

